PROFESSOR TAO HAI LIU (Orcid ID : 0000-0002-7286-6773)

Article type : Article

\title{
A multiscale methodology quantifying the sintering temperature dependent mechanical properties of oxide matrix composites
}

\author{
Ru Jiang ${ }^{a, 1}$, Lingwei Yang ${ }^{a, b, 1,{ }^{*}}$, Haitao Liu ${ }^{a,{ }^{*}}$, Wei Tan ${ }^{c,}{ }^{*}$, Xun Sun ${ }^{a}$, Haifeng Cheng a ${ }^{a}$ Weiguo Mao ${ }^{d}$ \\ ${ }^{a}$ Science and Technology on Advanced Ceramic Fibers and Composites Laboratory, National \\ University of Defense Technology, Changsha 410073, China \\ ${ }^{\mathrm{b}}$ IMDEA Materials Institute, C/Eric Kandel 2, 28906, Getafe, Madrid, Spain \\ ${ }^{\mathrm{C}}$ Engineering Department, University of Cambridge, Trumpington Street, Cambridge CB2 1PZ, UK \\ ${ }^{\mathrm{d}}$ School of Materials Science and Engineering, Xiangtan University, Xiangtan 411105, China
}

\begin{abstract}
A novel methodology combining multiscale mechanical testing and finite element modeling is proposed to quantify the sintering temperature dependent mechanical properties of oxide matrix The results showed a high temperature-sensitivity in the modulus/strength of $\mathrm{AS}$ fiber and $\mathrm{Al}_{2} \mathrm{O}_{3}$ matrix due to their phase transitions at $1200^{\circ} \mathrm{C}$, as revealed by instrumented nanoindentation technique. The interfacial strength, as measured by a novel fiber push-in technique, was also

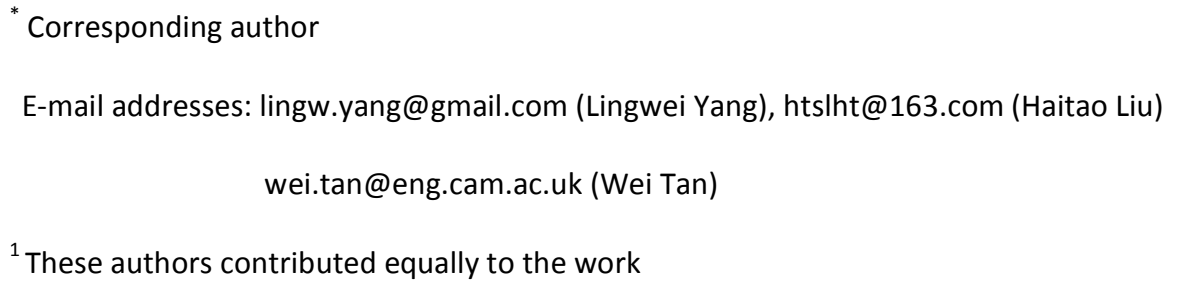
composites, like aluminosilicate (AS) fiber reinforced $\mathrm{Al}_{2} \mathrm{O}_{3}$ matrix $\left(\mathrm{AS}_{\mathrm{f}} / \mathrm{Al}_{2} \mathrm{O}_{3}\right)$ composite in this work.

This article has been accepted for publication and undergone full peer review but has not been through the copyediting, typesetting, pagination and proofreading process, which may lead to differences between this version and the Version of Record. Please cite this article as doi: $10.1111 /$ jace. 15473

This article is protected by copyright. All rights reserved. 
temperature dependent. Specially at $1200^{\circ} \mathrm{C}$, an interfacial phase reaction was observed, which bonded the interface tightly, as a result, the interfacial shear strength was up to $\approx 450 \mathrm{MPa}$. Employing the measured micro-mechanical parameters of the composite constituents enabled the prediction of deformation mechanism of the composite in microscale, which suggested a dominant role of interface on the ductile/brittle behavior of the composite in tension and shear. Accordingly, the $\mathrm{AS}_{\mathrm{f}} / \mathrm{Al}_{2} \mathrm{O}_{3}$ composite exhibited a ductile-to-brittle transition as the sintering temperature increased from $800^{\circ} \mathrm{C}$ to $1200^{\circ} \mathrm{C}$, due to the prohibition of interfacial debonding at higher temperatures, in good agreement with numerical predictions. The proposed multiscale methodology provides a powerful tool to study the mechanical properties of oxide matrix composites qualitatively and quantitatively.

Keywords: Ceramic matrix composites; Mechanical properties; Finite element analysis

\section{Introduction}

Oxide fiber reinforced oxide ceramic matrix (oxide/oxide) composites are promising candidates for high-temperature applications due to their inherent oxide natures which can prevent severe oxidation corrosion at extremely high temperatures. ${ }^{[1-6]}$ They are now found wide applications in next generation gas turbine engines where the combustion temperature is generally beyond 1000 ${ }^{\circ} \mathrm{C} .{ }^{[7]}$ Various oxide/oxide composite systems, like aluminosilicate (ALF family, Nextel 440, Nextel 720) or alumina (Nextel 610) fiber reinforced $\mathrm{Al}_{2} \mathrm{O}_{3}$ matrix composites have been fabricated previously by precursor infiltration pyrolysis, slurry infiltration or sol-gel technique. ${ }^{[8-11]}$ Particularly, the sol-gel technique is advantageous to prepare three-dimensional (3D) oxide/oxide composites due to its relatively low sintering temperature $\left(<1300^{\circ} \mathrm{C}\right)$, low shrinkage and reduced drying stresses. Moreover, it is a near net shape technique, and can be used to prepare large products with complex shapes. ${ }^{[12,13]}$ The sol-gel fabricated $\mathrm{Al}_{2} \mathrm{O}_{3}$ matrix composite is reported to have moderate tensile strength (>200 MPa), and can maintain $>90 \%$ of its room temperature strength after very high cycled fatigue loading at high temperatures, thus exhibiting an excellent thermal stability. ${ }^{[14-18]}$ Despite this, the toughness is still the main concern of this composites in their engineering services. Weakening interfacial interaction and fabricating porous matrix are two feasible methods to enhance the toughness by triggering crack energy dissipations at either the weak interface or the micro-cracks within the matrix.

It is well known that the macro-mechanical properties of oxide/oxide composites are mainly dominated by the micro-mechanical properties of fiber, matrix and fiber/matrix interface, which are more sensitive to sintering temperatures. ${ }^{[19,20]}$ For example, L.W. Yang, etc. have found a ductile-to-brittle transition of an AS fiber reinforced $\mathrm{SiO}_{2}\left(\mathrm{AS}_{\mathrm{f}} / \mathrm{SiO}_{2}\right)$ composite at a sintering temperature of $1200{ }^{\circ} \mathrm{C}$, due to the formation of an interfacial reaction zone, which arises significantly the interfacial strength and degrades severely the toughness of the composite. ${ }^{[20]}$ Compared to the $\mathrm{AS}_{\mathrm{f}} / \mathrm{SiO}_{2}$ composite, the $\mathrm{AS}$ fiber reinforced $\mathrm{Al}_{2} \mathrm{O}_{3}$ matrix $\left(\mathrm{AS}_{\mathrm{f}} / \mathrm{Al}_{2} \mathrm{O}_{3}\right)$ composite is

This article is protected by copyright. All rights reserved. 
more creep resistant, but is more thermal-sensitive because of the expecting phase transitions of both the AS fiber and the $\mathrm{Al}_{2} \mathrm{O}_{3}$ matrix at high temperatures. ${ }^{[21]}$ However, the underlying mechanism controlling the sintering temperature dependent mechanical properties of the typical oxide/oxide composites are still scarcely reported. This is mainly due to some experimental and modelling difficulties arisen from the length of scales under study (from microscale, mesoscale to macroscale) and the complexity in the structure of oxide/oxide composites, such as, firstly, accurate acquisitions of the micro-mechanical properties of the oxide fiber (diameter generally $\leq 10 \mu \mathrm{m}$ ), the oxide matrix and the fiber/matrix interface; secondly, prediction of the micro-mechanical property of the composite by using the measured localized mechanical properties of the composite constituents; and finally, correlation of the micro-mechanical properties with those macro-mechanical performances of the composites.

To this end, this work contributes to provide a bottom-to-up methodology to study the sintering temperature dependent mechanical properties of typical oxide/oxide composites by combining micro- and macro- mechanical testing techniques with finite element modeling in multiscale. The $\mathrm{AS}_{\mathrm{f}} / \mathrm{Al}_{2} \mathrm{O}_{3}$ composite was used as the material model for this study because of its temperature sensitivity in microstructure and mechanical properties. The methodology relies on a systematic measurement in the micro-mechanical properties of oxide fiber, oxide matrix and fiber/matrix interface by novel nanoindentation and fiber push-in techniques. This is followed by a computational finite element modeling to study the deformation mechanisms of the composite in tension, compression and shear, inputting the measured micro-mechanical parameters. This enables a deeper understanding in the dominant mechanism controlling the sintering temperature dependent mechanical properties of oxide/oxide composite, which is finally verified by the macro-mechanical testing, like the macro-tension and the single edge notch beam (SENB) employed in this work.

\section{Experimental and modeling procedures}

\subsection{Fabrication and microstructural characterization techniques}

3D woven AS fiber preforms (ALF-F2, from Nitivy ALF Co., Japan, sewing technique) were employed as reinforcements in the $\mathrm{AS}_{\mathrm{f}} / \mathrm{Al}_{2} \mathrm{O}_{3}$ composite. The given fiber volume fraction was $\approx 42 \%$. Details of the weaving structure can be accessed in Ref [20]. The organic coatings in the as-received AS fibers were removed by a thermal treatment at $500{ }^{\circ} \mathrm{C}$ for 2 hours in air. The $\mathrm{AS}_{\mathrm{f}} / \mathrm{Al}_{2} \mathrm{O}_{3}$ composite was fabricated by the sol-gel process using the $\mathrm{Al}_{2} \mathrm{O}_{3}$ sol (A-4-20, from Snowchemical S\&T Co., LTD, China) as matrix precursor. Detailed sol-gel process is as follows: the fiber preforms were firstly immersed in $\mathrm{Al}_{2} \mathrm{O}_{3}$ sols in vacuum for $>4$ hours to ensure adequate sol infiltration into the preform interiors. After that, the sol in the preform was converted to gel by drying the infiltrated preforms at $200{ }^{\circ} \mathrm{C}$ for 2 hours in air. This was followed by a sintering process at $800^{\circ} \mathrm{C}, 1000^{\circ} \mathrm{C}$ and $1200^{\circ} \mathrm{C}$ for 0.5 hour in air to fabricate the $\mathrm{Al}_{2} \mathrm{O}_{3}$ matrix. The sol-gel process was repeated $>12$ times until a relative composite weight increase $<1 \%$ was obtained. In order to explore in detail the sintering

This article is protected by copyright. All rights reserved. 
temperature dependent microstructure and mechanical properties of the as-fabricated $\mathrm{AS}_{\mathrm{f}} / \mathrm{Al}_{2} \mathrm{O}_{3}$ composite, pure AS fiber was also heat-treated and $\mathrm{Al}_{2} \mathrm{O}_{3}$ ceramic free of reinforcement was also fabricated at the same temperatures.

Phases in the AS fibers, the $\mathrm{Al}_{2} \mathrm{O}_{3}$ matrix and the $\mathrm{AS}_{\mathrm{f}} / \mathrm{Al}_{2} \mathrm{O}_{3}$ composite processed or fabricated at different temperatures were characterized by the X-ray diffraction (XRD) using monochromatic $\mathrm{CuKa}$ radiation inside a D8 ADVANCE diffractometer (Bruker, Germany). The morphologies of the $\mathrm{AS}_{\mathrm{f}} / \mathrm{Al}_{2} \mathrm{O}_{3}$ composites were characterized by optical microscopy and scanning electron microscopy (SEM, Hitachi FEG S4800). The interfacial microstructure was characterized by transmission electron microscopy (TEM, Tecnai F20), and the TEM foil was extracted from the composite by a 'lift-out' process inside a Helios 600i focused ion beam milling system.

\subsection{Micro- and macro- mechanical testing techniques}

The Young's modulus and hardness of the $A S$ fibers and $\mathrm{Al}_{2} \mathrm{O}_{3}$ matrix in the $\mathrm{AS}_{\mathrm{f}} / \mathrm{Al}_{2} \mathrm{O}_{3}$ composite were quantified by the instrumented nanoindentation technique on a finely polished composite cross-section, as shown in Fig. 1 (a). The test was performed in a load-controlled mode inside a Hysitron TI 950 Triboindenter $^{\mathrm{TM}}$ equipped with a Berkovich diamond indenter. The maximum applied force was $10 \mathrm{mN}$, thus yielding a penetration depth $>200 \mathrm{~nm}$ which was large enough to eliminate the effect of surface roughness. ${ }^{[22]}$ At least 10 tests were carried out to ensure the reproducibility of the results. The shear strength of the fiber/matrix interface was measured by the fiber push-in test, also inside the same Triboindenter ${ }^{\mathrm{TM}}$ system but using a flat punch (diameter: $3 \mu \mathrm{m}$ ), as shown in Fig. 1 (b). The loading was imposed perpendicular to the fiber cross-section in a displacement controlled mode, so that shear force was generated at the fiber/matrix interface, which can trigger Mode II cracking of the fiber/matrix interface. The maximum displacement was $2 \mu \mathrm{m}$ and the loading rate was $30 \mathrm{~nm} / \mathrm{s}$. Based on the obtained push-in curves, the interfacial shear strengths of different samples were evaluated by the shear-lag model. ${ }^{[23]}$ Detailed introduction of the push-in test can be accessed in reference ${ }^{[23]}$.

Macroscopic tensile tests of the $\mathrm{AS}_{\mathrm{f}} / \mathrm{Al}_{2} \mathrm{O}_{3}$ composite were performed on a dual-column CSC-1101 testing machine equipped with a $500 \mathrm{~N}$ load cell, based on the ASTM standards C1275-10. The tensile specimen was in a dog-bone like shape, having a gauge length $\approx 8 \mathrm{~mm}$ and the aspect ratio $>5$. The test was displacement controlled, and the displacement rate was $1 \mathrm{~mm} / \mathrm{min}$. Engineering stress and strain were calculated based on the recorded force and displacement data. For each composite, at least 3 tests were performed to ensure the reproducibility of the results.

The macro fracture toughness $\left(K_{\mathrm{IC}}\right)$ of $\mathrm{AS}_{\mathrm{f}} / \mathrm{Al}_{2} \mathrm{O}_{3}$ composite was measured by the SENB technique, according to the ASTME 399-74 standard. The dimensions of the SENB specimen were $\approx 40 \mathrm{~mm}$ in length, $\approx 3 \mathrm{~mm}$ in width and $\approx 6 \mathrm{~mm}$ in thickness. The notch was machined by metal bonded diamond cutting blade along the thickness direction. It was $\approx 3 \mathrm{~mm}$ long and $\approx 0.2 \mathrm{~mm}$ wide. The span

This article is protected by copyright. All rights reserved. 
dimension was $30 \mathrm{~mm}$ and the loading rate was also $0.05 \mathrm{~mm} / \mathrm{min}$. The fracture toughness was extracted based on:

$$
K_{\mathrm{IC}}=\frac{3 P L}{2 B H^{2}} a^{1 / 2} f(a / H)
$$

where $P$ is the critical loading leading to the fracture of the composite. $L$ is the testing span. $B$ and $H$ are the thickness and width of the specimen, respectively. $a$ is the pre-notch depth. $f(a / H)$ is the dimensionless function to calibrate the effect of pre-notch depth on the measured results. At least 5 samples were tested to obtain reproducible results. The crack propagation paths of the composites during SENB tests were observed in-situ by the local surface strain profile monitored by the digital image correction (DIC) technique. The strain evolution of the monitored region was observed by a high-resolution camera with a sampling rate of one image per second. The strain field data was post-processed by a commercial available DIC software (ARAMIS).

\subsection{Micromechanical model}

A 2D version of micromechanical model is presented here to study the deformation mechanism of the $\mathrm{AS}_{\mathrm{f}} / \mathrm{Al}_{2} \mathrm{O}_{3}$ composites as a function of sintering temperature at the microscale level, based on the measured micro-mechanical parameters of the $\mathrm{AS}$ fiber, the $\mathrm{Al}_{2} \mathrm{O}_{3}$ and the $\mathrm{AS}_{\mathrm{f}} / \mathrm{Al}_{2} \mathrm{O}_{3}$ interface. Fig. 2 shows a representative volume element (RVE) model which was assembled by randomly-oriented AS fibers (diameter $\approx 7 \mu \mathrm{m}$ ) and $\mathrm{Al}_{2} \mathrm{O}_{3}$ matrix in a $58 \mu \mathrm{m} \times 58 \mu \mathrm{m}$ coupon. The volume fraction was $\approx 50 \%$. The AS fiber and the $\mathrm{Al}_{2} \mathrm{O}_{3}$ matrix were modelled as isotropic linear and elastic solids due to their ceramic natures. The input Young's modulus and strength of both materials were obtained by the aforementioned nanoindentation technique. The fiber/matrix interface was modelled by a traction-separation law, as shown in Fig. 3, to capture the cohesive damage and the effect of friction occurring after fiber/matrix debonding. ${ }^{[24]}$ The elastic behavior was modelled in terms of an elastic constitutive matrix that related the normal and shear stresses to the corresponding separations across the interface. The traction stresses were defined as the cohesive forces acting along the normal and shear directions divided by the current area at each contact point. Damage initiation was governed by a quadratic stress criterion:

$$
\left(\frac{\tau_{s}}{\tau_{s}^{0}}\right)^{2}+\left(\frac{\tau_{t}}{\tau_{t}^{0}}\right)^{2}+\left(\frac{\tau_{n}}{\tau_{n}^{0}}\right)^{2} \leq 1
$$

where $\tau_{i}(i=n, s, t)$ are the traction stress vectors at the fiber/matrix interface in the in-plane shear $(\mathrm{s}, \mathrm{t})$ and normal $(\mathrm{n})$ directions, respectively, and $\tau_{i}^{0}(i=n, s, t)$ are the corresponding interfacial strength at each direction. Specially, the shear strength of the interface was measured in this work by the fiber push-in test, and the normal strength were estimated reasonably using equation $\tau_{n}^{0}=2 / 3 \tau_{s}^{0} .{ }^{[25]}$ Details about the cohesive element can be accessed in. ${ }^{[24]}$ The interface

This article is protected by copyright. All rights reserved. 
fracture energy in mode $\mathrm{I}, \mathcal{G}_{I c}$ is difficult to be experimentally measured. It was assumed reasonably in the range of $2-5 \mathrm{~J} / \mathrm{m}^{2}$. Similar values were used by other authors and were reported in the literature. ${ }^{[26-28]}$ In addition, the interface fracture energies in the shear modes were set equal to the matrix cracking fracture energy, $\mathcal{G}_{I I c}=100 \mathrm{~J} / \mathrm{m}^{2}$, a value similar to the one used. ${ }^{[26]} \mathrm{A}$ sensitivity study of these values indicates their effect on material behavior was only limited in the damage propagation regime. ${ }^{[29]}$

The RVE was discretized using wedge and brick finite elements for fibers and matrix with full Gauss integration (C3D6 and C3D8). It consisted of $\approx 20,000$ elements which represented a discretization fine enough to capture the large stress gradients between neighboring fibers. Periodic boundary condition (PBC) was applied to the node positions on opposite faces of the RVE. In order to predict the deformation mechanism of the composite, transverse tension, compression and shear simulations were finally carried out with ABAQUS /Standard 6.14 based on finite deformation theory. ${ }^{[30]}$

\section{Results and Discussion}

\subsection{Microstructure of $\mathrm{AS}_{f} / \mathrm{Al}_{2} \mathrm{O}_{3}$ Composites}

Fig. 4 shows a typical cross-section morphology of the $\mathrm{AS}_{\mathrm{f}} / \mathrm{Al}_{2} \mathrm{O}_{3}$ composite fabricated at $800{ }^{\circ} \mathrm{C}$. The $\mathrm{Al}_{2} \mathrm{O}_{3}$ matrix was relatively dense, especially within individual fiber tows after $>12$ sol-gel process (Fig. 4 b-c), but micro-scaled pores were still observed among fiber tows (Fig. 4a). The measured densities and the porosities of all the composites fabricated at $800 \sim 1000{ }^{\circ} \mathrm{C}$ were very similar, $\approx 2.0$ $\mathrm{g} / \mathrm{cm}^{3}$ and $\approx 18 \%$, respectively. The $\mathrm{Al}_{2} \mathrm{O}_{3}$ matrix was reinforced by the high-density 3D AS fibers (diameter $\approx 7 \mu \mathrm{m}$, Fig. 4d), which were distributed randomly inside the matrix in the latitudinal and longitudinal directions. The $\mathrm{AS}_{\mathrm{f}} / \mathrm{Al}_{2} \mathrm{O}_{3}$ composite was thus strengthened in such a way that both the $\mathrm{Al}_{2} \mathrm{O}_{3}$ matrix and the high strength $\mathrm{AS}$ fibers support the external load by load transfer at the fiber/matrix interfaces. However, as will be discussed later, the porosities inside the $\mathrm{Al}_{2} \mathrm{O}_{3}$ matrix can still limit strongly the tensile strength, and the brittleness of both the $\mathrm{AS}$ fiber and the $\mathrm{Al}_{2} \mathrm{O}_{3}$ matrix may lead to a poor damage tolerance of the composite.

Fig. 5 (a) shows the XRD patterns of the $\mathrm{AS}_{\mathrm{f}} / \mathrm{Al}_{2} \mathrm{O}_{3}$ composites as a function of sintering temperature. Sintered at $800^{\circ} \mathrm{C}$ and $1000^{\circ} \mathrm{C}$, the $\mathrm{AS}_{\mathrm{f}} / \mathrm{Al}_{2} \mathrm{O}_{3}$ composites were not well crystallized, and were mainly composed of amorphous $\mathrm{SiO}_{2}$ and $\gamma-\mathrm{Al}_{2} \mathrm{O}_{3}$ phases with low crystallization. Since the as-received AS fibers are mainly made up of fine-grained polycrystalline $\gamma-\mathrm{Al}_{2} \mathrm{O}_{3}(72 \%)$ and amorphous $\mathrm{SiO}_{2}(28 \%)$, as was further evidenced by XRD (Fig. 5b), the amorphous $\mathrm{SiO}_{2}$ found in the composite was mainly originated from the AS fiber. Instead, the $\mathrm{Al}_{2} \mathrm{O}_{3}$ matrix, after the sintering

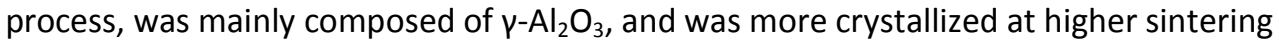
temperatures, as shown in Fig. 5 (c). Interestingly, phase transitions of both the AS fiber and the $\mathrm{Al}_{2} \mathrm{O}_{3}$ matrix were triggered at sintering temperature of $1200^{\circ} \mathrm{C}$ (Fig. $5 \mathrm{~b}-\mathrm{C}$ ), thus leading to a

This article is protected by copyright. All rights reserved. 
significant change in the crystallized structure of the $\mathrm{AS}_{\mathrm{f}} / \mathrm{Al}_{2} \mathrm{O}_{3}$ composite (Fig. 5a). Note the phase transition mechanism was different for each component. The phase transition occurring in the AS fiber was mainly due to a phase reaction between the amorphous $\mathrm{SiO}_{2}$ and $\mathrm{\gamma}-\mathrm{Al}_{2} \mathrm{O}_{3}$ at $1200{ }^{\circ} \mathrm{C}$, with the formation of a crystallized mullite phase $\left(3 \mathrm{Al}_{2} \mathrm{O}_{3} \cdot 2 \mathrm{SiO}_{2}\right)$ in the AS fiber ${ }^{[31]}$. Instead, a phase transition from $\mathrm{Y}-\mathrm{Al}_{2} \mathrm{O}_{3}$ to $\alpha-\mathrm{Al}_{2} \mathrm{O}_{3}$ was observed at $1200{ }^{\circ} \mathrm{C}$ in the $\mathrm{Al}_{2} \mathrm{O}_{3}$ matrix. ${ }^{[32]}$ Detailed analysis on the effect of such phase transition on the micro-mechanical property of both the AS fiber and the $\mathrm{Al}_{2} \mathrm{O}_{3}$ matrix has been performed with the help of instrumented nanoindentation technique, as will be discussed later.

\subsection{Micro-mechanical properties of fiber, matrix and interface}

In order to ascertain the effect of the microstructural changes in response to various sintering temperature on the fracture resistance of the $\mathrm{AS}_{\mathrm{f}} / \mathrm{Al}_{2} \mathrm{O}_{3}$ composite, instrumented nanoindentation tests were carried out in-situ on individual AS fibers and $\mathrm{Al}_{2} \mathrm{O}_{3}$ matrix from the finely polished composite cross-section (Fig. 4). Note nanoindentation testing on AS fiber is difficult to implement due to the limited volume of AS fiber. Here, the test was performed with a comparably small external load $(10 \mathrm{mN})$, which penetrated the nanoindenter into the AS fiber for $<300 \mathrm{~nm}$ (insert in Fig. 6a), thus the induced plastic stress field was fully constrained within the AS fiber. The measured Young's modulus and hardness of the AS fiber as a function of sintering temperature is shown in Fig. 6 (a). At 800 and $1000^{\circ} \mathrm{C}$, the Young's modulus of the AS fiber was $\approx 156 \mathrm{GPa}$, in consistent with what was reported by the filament tensile tests, and compared well with the provided value for the as-received fiber ${ }^{[31]}$. This suggests a stable microstructure of the AS fiber at this temperature range. The hardness of the AS fiber was $\approx 11.9 \mathrm{GPa}$. As the sintering temperature increased to $1200{ }^{\circ} \mathrm{C}$, the Young's modulus was increased evidently to $\approx 176 \mathrm{GPa},{ }^{[33]}$ and this must be a consequence of the mullite phase formation at this temperature within the AS fiber. However, the measured hardness was still decreased to $\approx 9.6 \mathrm{GPa}$. This can be explained by the formation of mullite phase and the grain growth of mullite at $1200^{\circ} \mathrm{C} .{ }^{[20,31]}$

Sintering temperature can have a more remarkable effect on the micro mechanical property of the $\mathrm{Al}_{2} \mathrm{O}_{3}$ matrix. Using the same loading-unloading segments, the obtained nanoindentation response of the matrix was quite different at different sintering temperatures, especially at $1200{ }^{\circ} \mathrm{C}$ (insert in Fig. $6 b$ ), due to the $\gamma \rightarrow \alpha$ phase transition of the $\mathrm{Al}_{2} \mathrm{O}_{3}$ matrix. As a reflect to this microstructural change, the measured Young's modulus and hardness plotted in Fig. 6 (b) were found increased significantly from $\approx 26.8 \mathrm{GPa}$ to $\approx 119.4 \mathrm{GPa}$ and from $\approx 2.72 \mathrm{GPa}$ to $\approx 7.30 \mathrm{GPa}$, respectively, as the sintering temperature increased to $1200^{\circ} \mathrm{C}$. Note the Young's modulus and hardness of $\gamma-\mathrm{Al}_{2} \mathrm{O}_{3}$ were also increased slightly from 800 to $1000{ }^{\circ} \mathrm{C}$, and this is expected due to the higher crystallized nature of $\gamma-\mathrm{Al}_{2} \mathrm{O}_{3}$ at higher temperatures, in accordance with the XRD results (Fig. 5c).

This article is protected by copyright. All rights reserved. 
Phase transitions of the $\mathrm{AS}$ fiber and the $\mathrm{Al}_{2} \mathrm{O}_{3}$ matrix can have a potential effect on the micro-mechanical properties of the fiber/matrix interface. For typical ceramic matrix composite, it is well-established that the interface mainly dominates the macro ductile/brittle performance of the composite. The interfacial shear strength was thus measured in-situ directly from the finely polished composite cross-section by a novel fiber push-in method. ${ }^{\left[23,{ }^{34]}\right.}$ Fig. 7 (a) depicts the typical push-in force-displacement curves of the $\mathrm{AS}_{\mathrm{f}} / \mathrm{Al}_{2} \mathrm{O}_{3}$ composites sintered at $800 \sim 1200{ }^{\circ} \mathrm{C}$. In response to the push-in load, the AS fiber and the surroundings were deformed elastically, which shown in the curve by a linear regime (stiffness, $S_{0}$ ). This was followed by the shear cracking of the fiber/matrix interface at a critical load $P_{\mathrm{c}}$ (inert in Fig. 7b), thus leading to a linear to non-linear transition of the push-in curve. By using a standard shear-lag model, ${ }^{[23]}$ the interfacial shear strength of fiber/matrix interface can be determined by:

$$
\tau=\frac{S_{0} P_{C}}{2 \pi^{2} r^{3} E_{f}}
$$

here, $r$ is the radius of the AS fiber $(\approx 3.5 \mu \mathrm{m})$. $E_{\mathrm{f}}$ is the Young's modulus of AS fiber, and was measured by the nanoindentation technique. The interfacial shear strength measured in each composite as a function of sintering temperature is thus plotted in Fig. 7 (b). At 800 and $1000{ }^{\circ} \mathrm{C}$, the interfacial shear strength was comparably low, <150 MPa, which is in accordance with a recent report in the $\mathrm{AS}_{\mathrm{f}} / \mathrm{SiO}_{2}$ composite. ${ }^{[20]}$ This weak interfacial feature in the typical oxide/oxide composite is in contrast to those traditional ceramic matrix composites where interfacial reaction generally occurred at fiber/matrix interface, thus forming strong interfacial interactions. ${ }^{[35]}$ Interestingly, the interfacial shear strength was increased significantly to $\approx 450 \mathrm{MPa}$, as the composite was sintered at $1200^{\circ} \mathrm{C}$. Note at this temperature, phase transitions in both the AS fiber and the $\mathrm{Al}_{2} \mathrm{O}_{3}$ matrix led to the change in the interfacial microstructure, which may alter the mechanical property of the interface. Despite this, the extremely strong shear property of fiber/matrix interface is more likely a consequence of interfacial reaction. The potential mechanism was verified by a detailed TEM characterization of a localized interfacial zone in the $1200{ }^{\circ} \mathrm{C}$ sintered composite, as shown in Fig. 8. Interestingly, an interfacial reaction zone was observed between the AS fiber and the mullite matrix, which bonded strongly the AS fiber and the $\mathrm{Al}_{2} \mathrm{O}_{3}$ matrix. It was $\approx 30$ $\mathrm{nm}$ in thickness, and was in a polycrystalline structure. Similar interfacial reaction has been also observed in other AS fiber reinforced $\mathrm{Al}_{2} \mathrm{O}_{3}$ matrix composite system, and is possibly dominated by the reaction between the $\mathrm{SiO}_{2}$ phase at the AS fiber surface and the remaining $\gamma-\mathrm{Al}_{2} \mathrm{O}_{3}$ phase in the $\mathrm{Al}_{2} \mathrm{O}_{3}$ matrix. ${ }^{[36]}$

This article is protected by copyright. All rights reserved. 


\subsection{Finite element modeling}

Finite element model was presented to investigate the deformation mechanisms of the $\mathrm{AS}_{\mathrm{f}} / \mathrm{Al}_{2} \mathrm{O}_{3}$ composites in microscale under uniaxial tensile, compressive and shear loading, inputting the measured micro-mechanical parameters of the AS fiber, the $\mathrm{Al}_{2} \mathrm{O}_{3}$ matrix and the $\mathrm{AS} / \mathrm{Al}_{2} \mathrm{O}_{3}$ interface, as listed in Table 1. Fig. 9 plots the predicted stress-strain curves of the RVE under transverse tensile loading as a function of sintering temperature. In all cases, the RVE was deformed elastically up to $<0.2$ strain. The predicted tensile modulus $E_{\mathrm{T}}$ of the RVE is summarized in Table 2 . The predicted tensile moduli $\left(E_{\mathrm{T}}\right)$ of the composites sintered at $800^{\circ} \mathrm{C}$ and $1000{ }^{\circ} \mathrm{C}$ were $58.7 \mathrm{GPa}$ and $72.5 \mathrm{GPa}$, respectively. It was increased evidently to $169 \mathrm{GPa}$ at even higher sintering temperature $\left(1200^{\circ} \mathrm{C}\right)$. Based on the localized mechanical analysis of the composite constituents in the above section, this result is mainly attributed to the $\gamma \rightarrow \alpha$ phase transition of the $\mathrm{Al}_{2} \mathrm{O}_{3}$ matrix where the measured Young's modulus was $\approx 5$ folders higher at $1200^{\circ} \mathrm{C}$. For the $\mathrm{AS}_{\mathrm{f}} / \mathrm{Al}_{2} \mathrm{O}_{3}$ composites sintered at $800{ }^{\circ} \mathrm{C}$ and $1000^{\circ} \mathrm{C}$, the elastic deformation was interrupted by fiber/matrix debonding, which was marked by a transition of stress-strain curves from linear to non-linear region. This is mainly due to the relative weak interfacial strength at $800^{\circ} \mathrm{C}$ and $1000^{\circ} \mathrm{C}$ (Fig. 7), which gave rise to increasing failure sites at the fiber/matrix interface, and to the degradation of the predicted tensile strength $\left(\sigma_{\mathrm{T}}\right)$ of the RVE, as also listed in Table 2. After the interfacial failure initiated, the $\mathrm{Al}_{2} \mathrm{O}_{3}$ matrix mainly dominated the non-linear deformation of the RVE until ultimate failure, triggered by damages accumulated at the matrix ligaments. The interfacial failure was not observed in the $1200^{\circ} \mathrm{C}$ sintered composite where brittle fracture occurred following the elastic deformation with a much higher failure strength $\sigma_{\mathrm{T}}(546.4 \mathrm{MPa})$.

Fig. 10 shows the predicted stress-strain curves of the RVE under transverse compressive loading as a function of sintering temperature. Unlike the tensile response, the RVE in compression was mainly deformed elastically until brittle fracture, without debonding of interfaces in all cases. As a result, the composites can sustain a relatively higher level of stress $\left(\sigma_{c}\right)$ under transverse compression, but the compressive moduli of the RVE $\left(E_{\mathrm{c}}\right)$, as listed in Table 2, was still similar to that obtained in tension. It is noticeable that the failure of the RVE in compression was initiated by shear banding inclined to the loading axis.

The stress-strain curves and stress contours of the RVE under shear loading perpendicular to fiber direction are depicted in Fig. 11. In all cases, the initial elastic deformation was always followed by a strain-hardening behavior. For the composites sintered at $800^{\circ} \mathrm{C}$ and $1000^{\circ} \mathrm{C}$, remarkable shear bands in an orientation of $45^{\circ}$ was observed. The dominant failure mode in these cases was interface debonding, as highlighted in the insert image in Fig. 11 . The strong interface bonding strength $(\approx 450$ $\mathrm{MPa}$ ) for the composite sintered at $1200^{\circ} \mathrm{C}$ impeded the interfacial failure, with limited debonding sites observed in the deformed RVE. The predicted shear modulus of composite sintered at $1200^{\circ} \mathrm{C}$ was $\approx 2.5$ times higher than those sintered at $800^{\circ} \mathrm{C}$ and $1000^{\circ} \mathrm{C}$, given in Table 2 . The shear strength was determined by the $0.2 \%$ offset strain point by translating the initial elasticity line. The predict

This article is protected by copyright. All rights reserved. 
shear strengths were very close to the inputted interfacial shear strength, which again confirms that the interfacial failure dominated the overall failure mode of the RVE under shear loading.

\subsection{Macro-mechanical properties of the composites}

The FE modeling of the $\mathrm{AS}_{\mathrm{f}} / \mathrm{Al}_{2} \mathrm{O}_{3}$ composite based on the microscale RVE provides a good indication of 2D failure mechanism in tension, compression and shear. This model can be extended into a full model considering the 3D woven architecture in the future work. The predicted failure mechanism was finally verified in this section by macroscale mechanical testing of the composite. Fig. 12 shows the tensile stress-strain curves of the $\mathrm{AS}_{\mathrm{f}} / \mathrm{Al}_{2} \mathrm{O}_{3}$ composite sintered at $800^{\sim} 1200^{\circ} \mathrm{C}$. At higher sintering temperature, the measured tensile moduli $\left(E_{T}^{*}\right.$, Table 3$)$ of the composite was higher. Despite that the composite was in a 3D woven structure while the RVE in FEM was unidirectional coupon, the $E_{T}^{*}$ for the $800^{\circ} \mathrm{C}$ sintered composites were close to the predicted values. At even higher sintering temperature, the discrepancy between the predicted and the measured $E_{T}^{*}$ was larger. For instance, for the composite sintered at $1200^{\circ} \mathrm{C}$, the $E_{T}^{*}$ was almost $\approx 2.5$ times lower than the predicted result. This must be a consequence of the porosity formed in the composite, which was not considered in the FE modeling. The effect of porosity was more evident on the tensile strength of the composite, as tensile failure was triggered by stress concentrations at the void. The measured tensile strength $\left(\sigma_{T}^{*}\right)$, as listed in Table 3 , was found decreased from $\approx 148.1 \mathrm{MPa}$ to $\approx 78.5 \mathrm{MPa}$ as the sintering temperature increased from $800^{\circ} \mathrm{C}$ to $1200^{\circ} \mathrm{C}$. In contrast, a reversed trend was observed in numerical results where the predicted strength was increased at higher sintering temperature. This contradiction is explained by the higher brittle nature of the composite (inserts in Fig. 12) where the pre-existing cracks are prone to trigger catastrophic failure of the composite sintered at higher temperature. Nevertheless, the FEM predicts well the ductile/brittle transition of the composite sintered at different temperatures, and reinforced the conclusion that the macro mechanical performance was mainly dominated by the interfacial property which was also dependent on the sintering temperature.

Since the main concern of oxide/oxide composites in engineering applications is their catastrophic failures when subjected to complex loading, the macro fracture toughness of the $\mathrm{AS}_{\mathrm{f}} / \mathrm{Al}_{2} \mathrm{O}_{3}$ composite as a function of sintering temperature was finally measured by the SENB test, and is plotted in Fig. 13 (a). As expected, the 800 and $1000^{\circ} \mathrm{C}$ sintered composites were ductile, having comparably large fracture toughness, $\approx 5.18 \mathrm{MPa} \bullet \mathrm{m}^{1 / 2}$ and $\approx 4.78 \mathrm{MPa} \bullet \mathrm{m}^{1 / 2}$, respectively. The progressive crack propagation by DIC showed evidently crack deflection at the cracking path, due to the weak interfacial properties of the composites. Note the toughening mechanisms like fiber pull-out, interfacial debonding, etc., were observed from the fracture surface of the composite after the SENB test, Fig. 13 (b). A ductile-to-brittle transition was also observed at $1200^{\circ} \mathrm{C}$, in agreement with the previous analysis. This was also captured by the DIC snapshots which show direct cracking propagation behavior in the composite. As a result, the fracture toughness of the composite was $\approx 6$ times lower, $\approx 0.84 \mathrm{MPa} \bullet \mathrm{m}^{1 / 2}$. The fracture surface, as shown in Fig. 13 (d), was flat, indicating a

This article is protected by copyright. All rights reserved. 
cracking propagation which penetrated through the AS fiber and the Al2O3 without any defection at the interface, due to the pretty strong interfacial strength.

\section{Conclusions}

A novel methodology combining the multiscale mechanical testing and finite element modeling techniques is proposed in this work to study the sintering temperature dependent mechanical properties of oxide matrix composites. A sol-gel fabricated aluminosilicate (AS) fiber reinforced alumina matrix $\left(\mathrm{AS}_{\mathrm{f}} / \mathrm{Al}_{2} \mathrm{O}_{3}\right)$ composite system sintered at $800 \sim 1200{ }^{\circ} \mathrm{C}$ was used as material model for this study. Based on this multiscale methodology, the following conclusions can be drawn:

(1) The micro-mechanical properties of the $\mathrm{AS}$ fiber, the $\mathrm{Al}_{2} \mathrm{O}_{3}$ matrix and the $\mathrm{AS}_{\mathrm{f}} / \mathrm{Al}_{2} \mathrm{O}_{3}$ interface were sintering-temperature dependent, due to their temperature sensitivities in the microstructures. Specially, the $\gamma \rightarrow \alpha$ phase transition in the $\mathrm{Al}_{2} \mathrm{O}_{3}$ matrix can increase significantly the Young's modulus and the strength (hardness), as revealed by nanoindentation technique. In addition, by implementing a novel fiber push-in technique, the measured shear strength of the $\mathrm{AS}_{\mathrm{f}} / \mathrm{Al}_{2} \mathrm{O}_{3}$ interface was also remarkably increased in the $1200^{\circ} \mathrm{C}$ sintered composite. Based on detailed transmission electron microscopy analysis, this was mainly due to the phase reactions at the interface between the amorphous silica in the AS fiber and the remaining $\gamma-\mathrm{Al}_{2} \mathrm{O}_{3}$ in the matrix.

(2) Finite element modeling prediction in the deformation mechanism, based on the obtained micro-mechanical properties of the composite constituents, showed a dominant role of the $\mathrm{AS}_{\mathrm{f}} / \mathrm{Al}_{2} \mathrm{O}_{3}$ interface on the ductile/brittle performance of the composite in tension and shear deformation. In detail, the 800 and $1000^{\circ} \mathrm{C}$ sintered composites were ductile, due to their comparably weak interfacial strength, while the $1200{ }^{\circ} \mathrm{C}$ sintered composite was much brittle, due to the reaction controlled interfacial nature. As a reflect to the $\gamma \rightarrow \alpha$ phase transition in the $\mathrm{Al}_{2} \mathrm{O}_{3}$ matrix, the prediction also showed a much higher Young's modulus for the $1200^{\circ} \mathrm{C}$ sintered composite.

(3) The predictions in the ductile/brittle behavior and in the Young's modulus of the composite correlated well with the experimental results based on the macro-tensile tests. The measured macroscopic tensile strengths as a function of sintering temperature were inferior to the predicted strengths from finite element models. This was mainly attributed to the porosities existed in the composites, triggering localized brittle fracture and consequent macroscopic tensile failure.

(4) Fiber pull-out events promoted by a relative low interfacial shear strength led to $\approx 6$ times higher measured fracture toughness of the $800-1000{ }^{\circ} \mathrm{C}$ sintered composite than that of composites sintered at $1200{ }^{\circ} \mathrm{C}$. This highlights the toughening mechanisms from weak interface

This article is protected by copyright. All rights reserved. 


\section{Acknowledgements}

Lingwei Yang greatly appreciates the financial support from the China Scholarship Council (grant number: 201306110007) and the National University of Defense Technology.

\section{References}

[1] Zok FW. Developments in oxide fiber composites. J Am Ceram Soc. 2006;89; 3309-3324.

[2] Zawada LP, Randall SH, Lee SS, Staehler J. Characterization and high-temperature mechanical behavior of an oxide/oxide composite. J Am Ceram Soc. 2003;86: 981-990.

[3] Mehrman JM, Ruggles-Wrenn MB, Baek SS. Influence of hold times on the elevated-temperature fatigue behavior of an oxide-oxide ceramic composite in air and in steam environment. Compos Sci Technol. 2007;67:1425-1438.

[4] Volkmann E, Tushtev K, Koch D, Wilhelmi C, Göring J, Rezwan K. Assessment of three oxide/oxide ceramic matrix composites: Mechanical performance and effects of heat treatments. Compos A. 2015;68:19-28.

[5] Di Salvo DT, Sackett EE, Johnston RE, Thompson D, Andrews P, Bache MR. Mechanical characterisation of a fibre reinforced oxide/oxide ceramic matrix composite. J Eur Ceram Soc. 2015;35:4513-4520.

[6] Kanka B, Schneider H. Aluminosilicate fiber mullite matrix composites with favorable high temperature properties. J Eur Ceram Soc. 2006;20:619-623.

[7] Staehler JM, Zawada LP. Performance of four ceramic-matrix composite divergent flap inserts following ground testing on an F110 turbofan engine. J Am Ceram Soc. 2000;83:1727-1738.

[8] Lange FF, Tu WC, Evans AG. Processing of damage-tolerant, oxidation-resistant ceramic matrix composites by a precursor infiltration and pyrolysis method. Mater Sci Eng A. 1995;195:145-150.

[9] Wang Y, Liu HT, Cheng HF, Wang J. Interface engineering of fiber-reinforced all-oxide composites fabricated by the sol-gel method with fugitive pyrolytic carbon coatings. Compos B.

2015;75:86-94.

[10] Kaya C, Kaya F, Butler EG, Boccaccini AR, Chawla KK. Development and characterisation of high-density oxide fibre-reinforced oxide ceramic matrix composites with improved mechanical properties. J Eur Ceram Soc. 2009;29:1631-1639.

This article is protected by copyright. All rights reserved. 
[11] Russell-Floyd RS, Harris B, Cooke RG, Laurie J, Hammett FW, Jones RW, Wang TH. Application of sol-gel processing techniques for the manufacture of fiber-reinforced ceramics. J Am Ceram Soc. 1993;76(10):2635-2643.

[12] Naskar MK, Basu K, Chatterjee M. Sol-gel approach to near-net-shape oxide-oxide composites reinforced with short alumina fibres-The effect of crystallization. Ceram Int.

2009;35:3073-3079.

[13] Volkmann E, Evangelista LL, Tushtev K, Koch D, Wilhelmi C, Rezwan K. Oxidation-induced microstructural changes of a polymer-derived Nextel ${ }^{\mathrm{TM}} 610$ ceramic composite and impact on the mechanical performance. J Mater Sci. 2014;49:710-719.

[14] Jurf R, Butner S. Advances in oxide-oxide CMC. J Eng Gas Turbines Power. 2000;122(2):202-205.

[15] Ruggles-Wrenn MB, Mall S, Eber CA, Harlan LB. Effects of steam environment on high-temperature mechanical behavior of $\mathrm{Nextel}^{\mathrm{TM}} 720$ /alumina (N720/A) continuous fiber ceramic composite. Compos A. 2006;37:2029-2040.

[16] Mall S, Ahn JM. Frequency effects on fatigue behavior of Nextel720(TM)/ alumina at room temperature. J Eur Ceram Soc. 2008;28(14):2783-2789.

[17] Mehrman JM, Ruggles-Wrenn MB, Baek SS. Influence of hold times on the elevated-temperature fatigue behavior of an oxide-oxide ceramic composite in air and in steam environment. Compos Sci Technol. 2006; 67(7-8):1425-1438.

[18] Simon RA. Progress in processing and performance of porous-matrix oxide/ oxide composites. Int J Appl Ceram Technol. 2005;2(2):141-149.

[19] Wang Y, Cheng HF, Liu HT, Wang J. Effects of sintering temperature on mechanical properties of 3D mullite fiber (ALF FB3) reinforced mullite composites. Ceram Int. 2013;39:9229-9235.

[20] Yang LW, Wang JY, Liu HT, Jiang R, Cheng HF. Sol-gel temperature dependent ductile-to-brittle transition of aluminosilicate fiber reinforced silica matrix composite. Compos B. 2017;119:79-89.

[21] Askarinejad S, Rahbar N, Sabelkin V, Mall S. Mechanical behavior of a notched oxide/oxide ceramic matrix composite in combustion environment: Experiments and simulations. Compos Struct. 2015;127:77-86.

[22] Oliver WC, Pharr GM, An improved technique for determining hardness and elastic modulus using load and displacement sensing indentation experiments. J Mater Res. 1992;7(06):1564-1583.

This article is protected by copyright. All rights reserved. 
[23] Rodriguez M, Molina-Aldareguía JM, González C, Lorca J. A methodology to measure the interface shear strength by means of the fiber push-in test. Compos Sci Technol.

2012;72(15):1924-1932.

[24] Simulia. Abaqus 6.12 documentation. Providence, Rhode Island, US. 2012.

[25] Ogihara S, Koyanagi J. Investigation of combined stress state failure criterion for glass fiber/epoxy interface by the cruciform specimen method. Compos Sci Technol. 2010;70:143-150.

[26] Naya F, González C, Lopes CS, Veen V, Pons F. Computational micromechanics of the transverse and shear behavior of unidirectional fiber reinforced polymers including environmental effects. Compos A. 2017;92:146-157.

[27] Melro AR, Camanho PP, Andrade Pires FM, Pinho ST. Micromechanical analysis of polymer composites reinforced by unidirectional fibres: Part II-Micromechanical analyses. Int J Solids Struct. 2013;50(11-12):1906-1915.

[28] Vaughan TJ, McCarthy CT. A combined experimental-numerical approach for generating statistically equivalent fibre distributions for high strength laminated composite materials. Compos Sci Technol. 2010;70:291-297.

[29] Tan W, Naya F, Yang L, Chang T, Falzon, BG, Zhan L, Molina-Aldareguia JM, González C, Llorca J. The role of interfacial properties on the intralaminar and interlaminar damage behaviour of unidirectional composite laminates: Experimental characterization and multiscale modelling. Compos B. 2018;138:206-221.

[30] ABAQUS V. 6.14 Documentation. Dassault Systemes Simulia Corporation. 2014.

[31] Wang Y, Cheng HF, Liu HT, Wang J. Microstructure and room temperature mechanical properties of mullite fibers after heat-treatment at elevated temperatures. Mater Sci Eng A. 2013;578:287-293.

[32] Stösser R, Scholz G, Buzaré J, Silly G, Nofz M, Schultze D. A magnetic resonance investigation of the process of corundum formation starting from sol-gel precursors. J Am Ceram Soc. 2005;88(10):2913-2922.

[33] Gong JH, Wu JJ, Guan ZD, Examination of the Indentation Size Effect in Low-load Vickers Hardness Testing of Ceramics. J Eur Ceram Soc. 1999;19:2625-2631.

[34] Yan W, Pun CL, Wu Z, Simon GP. Some issues on nanoindentation method to measure the elastic modulus of particles in composites. Compos B. 2011;42:2093-20977.

[35] Yang LW, Liu HT, Cheng HF. Processing-temperature dependent micro- and macro-mechanical properties of SiC fiber reinforced SiC matrix composites. Compos B.2017;129:152-161.

This article is protected by copyright. All rights reserved. 
[36] Schmucker M, Kanka B, Schneider H. Temperature-induced fiber/matrix interaction in porous alumino silicate ceramic matrix composites. J Eur Ceram Soc. 2000;20:2491-2497.

This article is protected by copyright. All rights reserved. 
Table 1 Measured micro-mechanical properties of the AS fiber, the $\mathrm{Al}_{2} \mathrm{O}_{3}$ matrix and the fiber/matrix interface

\begin{tabular}{|c|c|c|c|c|c|c|c|}
\hline \multirow{3}{*}{$\begin{array}{l}\text { Temp } \\
\left({ }^{\circ} \mathrm{C}\right)\end{array}$} & \multicolumn{3}{|c|}{ AS fiber } & \multicolumn{3}{|c|}{$\mathrm{Al}_{2} \mathrm{O}_{3}$ matrix } & \multirow{2}{*}{$\begin{array}{c}\text { Interface } \\
\tau_{\text {int }}\end{array}$} \\
\hline & $E_{\mathrm{f}}$ & $\sigma_{f}$ & $H$ & $E_{\mathrm{m}}$ & $\sigma_{\mathrm{m}}$ & $H$ & \\
\hline & (GPa) & (MPa) & (GPa) & (GPa) & (MPa) & (GPa) & (MPa) \\
\hline 800 & 156.0 & 3960.0 & 11.9 & 26.8 & 906.7 & 2.7 & 90.0 \\
\hline 1000 & 156.0 & 3960.0 & 11.9 & 27.5 & 1000.0 & 3.0 & 145.0 \\
\hline 1200 & 176.0 & 3200.0 & 9.6 & 119.4 & 2433.3 & 7.3 & 450.0 \\
\hline
\end{tabular}

Table 2 Predicted elastic properties of $\mathrm{AS}_{\mathrm{f}} / \mathrm{Al}_{2} \mathrm{O}_{3}$ composite RVE under transverse tension, compression and shear loading.

\begin{tabular}{ccccccc}
\hline Temp $\left({ }^{\circ} \mathrm{C}\right)$ & $E_{\mathrm{T}}(\mathrm{GPa})$ & $\sigma_{\mathrm{T}}(\mathrm{MPa})$ & $E_{\mathrm{C}}(\mathrm{GPa})$ & $\sigma_{\mathrm{C}}(\mathrm{MPa})$ & $G_{12}(\mathrm{GPa})$ & $S_{12}(\mathrm{MPa})$ \\
\hline 800 & 58.7 & 133.8 & 56.2 & 608.2 & 2.6 & 90.1 \\
1000 & 72.5 & 187.0 & 59.7 & 696.0 & 2.9 & 132.4 \\
1200 & 169.0 & 546.4 & 141.4 & 1926.1 & 8.1 & 479.2 \\
\hline
\end{tabular}

This article is protected by copyright. All rights reserved. 
Table 3 The measured $E_{T}^{*}$ and $\sigma_{T}^{*}$ of the $\mathrm{AS}_{\mathrm{f}} / \mathrm{Al}_{2} \mathrm{O}_{3}$ composite by macro-tensional tests

\begin{tabular}{ccc}
\hline Temp $\left({ }^{\circ} \mathrm{C}\right)$ & $E_{T}^{*}(\mathrm{GPa})$ & $\sigma_{T}^{*}(\mathrm{MPa})$ \\
\hline 800 & 43.8 & 148.1 \\
1000 & 55.4 & 122.4 \\
1200 & 63.9 & 78.5 \\
\hline
\end{tabular}

This article is protected by copyright. All rights reserved. 


\section{Figure list:}

Fig. 1 Testing schematics of (a) Nanoindentation and (b) Fiber push-in techniques.

Fig. 2 Schematic 2D view of the microscale RVE model showing the fiber distribution, FEM mesh and cohesive interface.

Fig. 3 Schematic representation of (a) cohesive surface and (b) traction-separation response with isotropic shear behavior.

Fig. 4 Typical cross-section morphology of $\mathrm{AS}_{\mathrm{f}} / \mathrm{Al}_{2} \mathrm{O}_{3}$ composite fabricated at $800^{\circ} \mathrm{C}$ : (a, b) optical microscopy images, (c, d) SEM images.

Fig. 5 XRD patterns of (a) $\mathrm{AS}_{\mathrm{f}} / \mathrm{Al}_{2} \mathrm{O}_{3}$ composites, (b) individual $\mathrm{AS}$ fiber and (c) $\mathrm{Al}_{2} \mathrm{O}_{3}$ monolithic ceramic sintered at $800^{\sim} 1200^{\circ} \mathrm{C}$.

Fig. 6 Young's modulus and hardness of (a) AS fiber and (b) $\mathrm{Al}_{2} \mathrm{O}_{3}$ matrix in $\mathrm{AS}_{\mathrm{f}} / \mathrm{Al}_{2} \mathrm{O}_{3}$ composites as a function of sintering temperatures. The inserts are the typical nanoindentation force-penetration curves for both components.

Fig. 7 (a) Typical Push-in curves and (b) interfacial shear strength of $\mathrm{AS}_{\mathrm{f}} / \mathrm{Al}_{2} \mathrm{O}_{3}$ composites as a function of sol-gel temperature. The insert is a typical SEM image showing the failure of interface after the test.

Fig. 8 TEM characterization of fiber/matrix interface in the $1200^{\circ} \mathrm{C}$ fabricated composite.

Fig. 9 Predicted uniaxial tensile stress-strain curves and stress contours of $\mathrm{AS}_{\mathrm{f}} / \mathrm{Al}_{2} \mathrm{O}_{3}$ composites as a function of sol-gel temperature.

Fig. 10 Predicted uniaxial compressive stress-strain curves and stress contours of $A_{\mathrm{f}} / \mathrm{Al}_{2} \mathrm{O}_{3}$ composites as a function of sol-gel temperature.

Fig. 11 Predicted uniaxial shear stress-strain curves and stress contours of $\mathrm{AS}_{\mathrm{f}} / \mathrm{Al}_{2} \mathrm{O}_{3}$ composites as a function of sol-gel temperature.

Fig. 12 Tensile stress-strain curves of the $\mathrm{AS}_{\mathrm{f}} / \mathrm{Al}_{2} \mathrm{O}_{3}$ composites as a function of sintering temperature. The inserts are the optical images of the fractured specimen, also showing ductile/brittle transition at higher sintering temperatures.

Fig. 13 Typical SENB force-displacement curves of $\mathrm{AS}_{\mathrm{f}} / \mathrm{Al}_{2} \mathrm{O}_{3}$ composites sintered at (a) $800{ }^{\circ} \mathrm{C}$ and (c) $1200{ }^{\circ} \mathrm{C}$ and fracture surfaces of the composites sintered at (b) $800{ }^{\circ} \mathrm{C}$ and (d) $1200{ }^{\circ} \mathrm{C}$. The inserts are the DIC measured strain contour of the 800 and $1000^{\circ} \mathrm{C}$ fabricated composite during the SENB deformation, showing progressive crack propagation.

This article is protected by copyright. All rights reserved. 
(a)

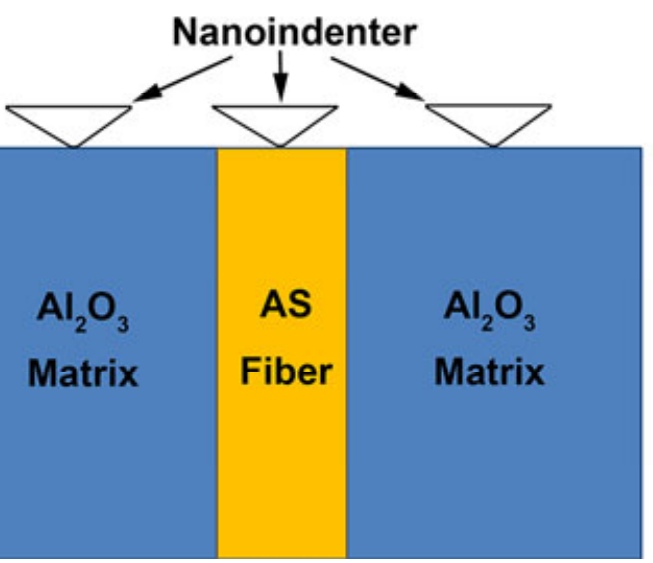

(b)

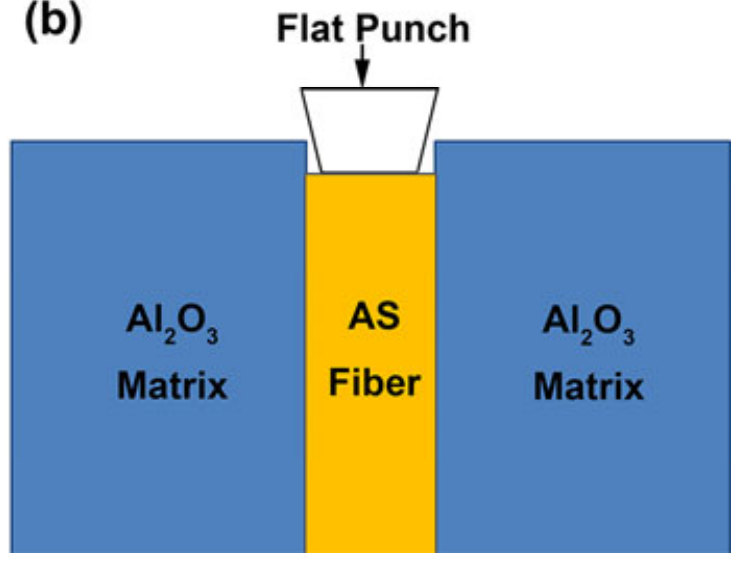

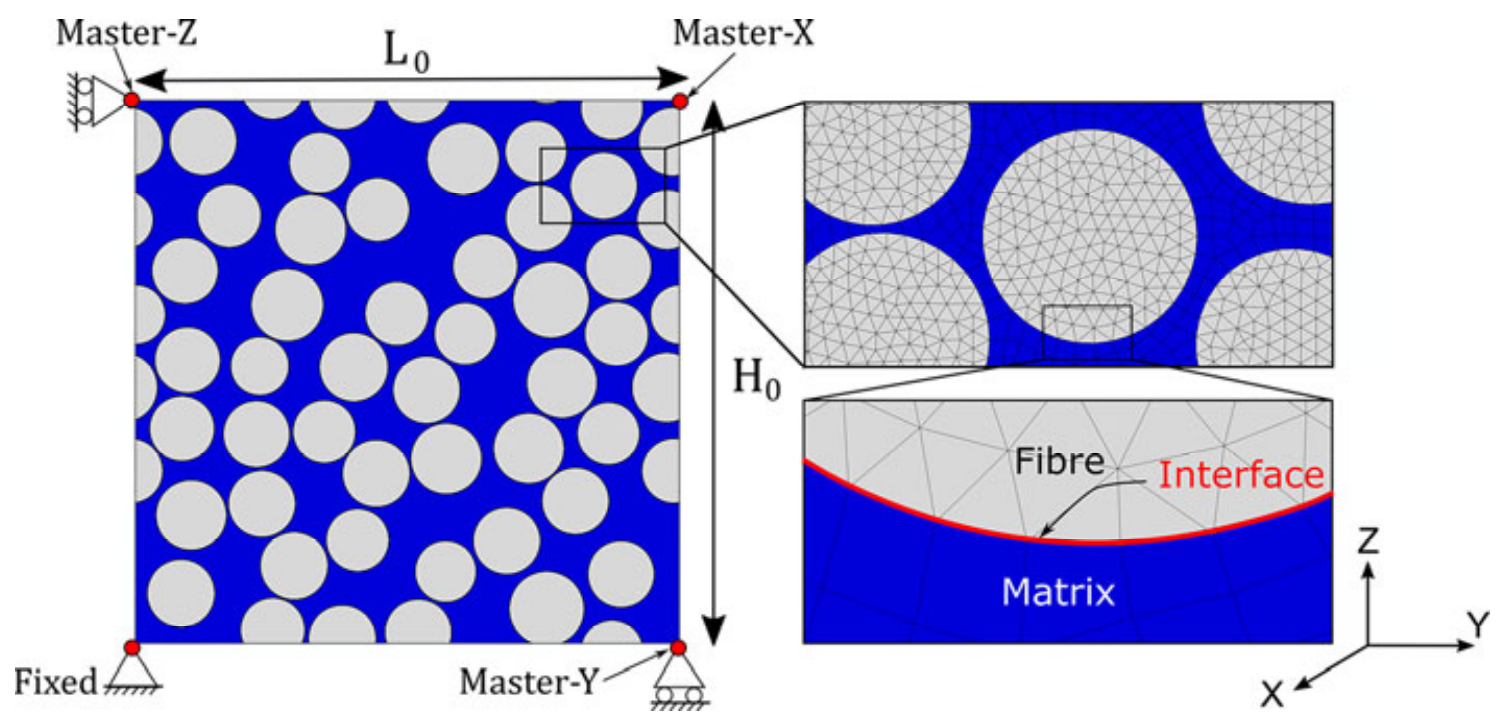

(a)

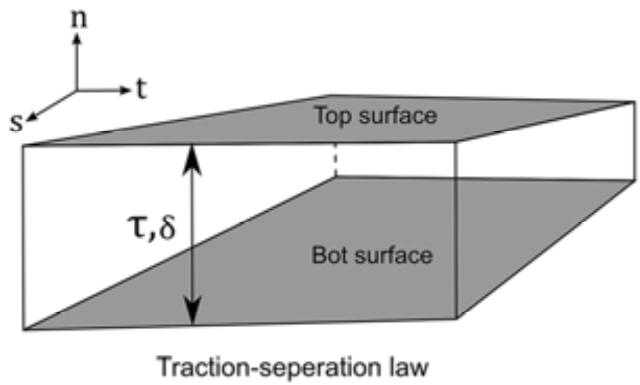

(b)

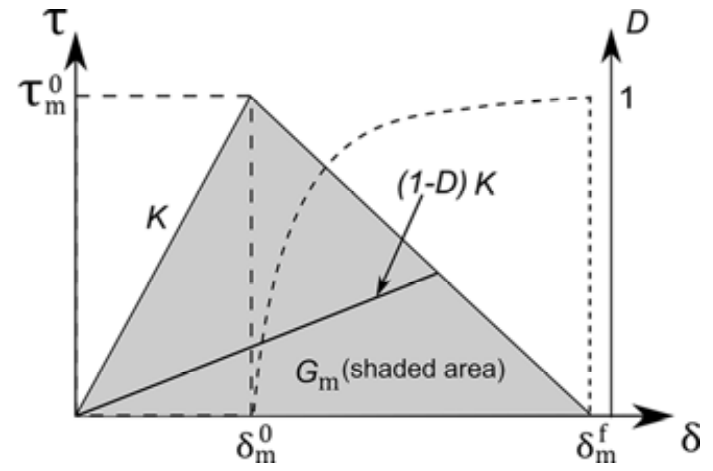

This article is protected by copyright. All rights reserved. 


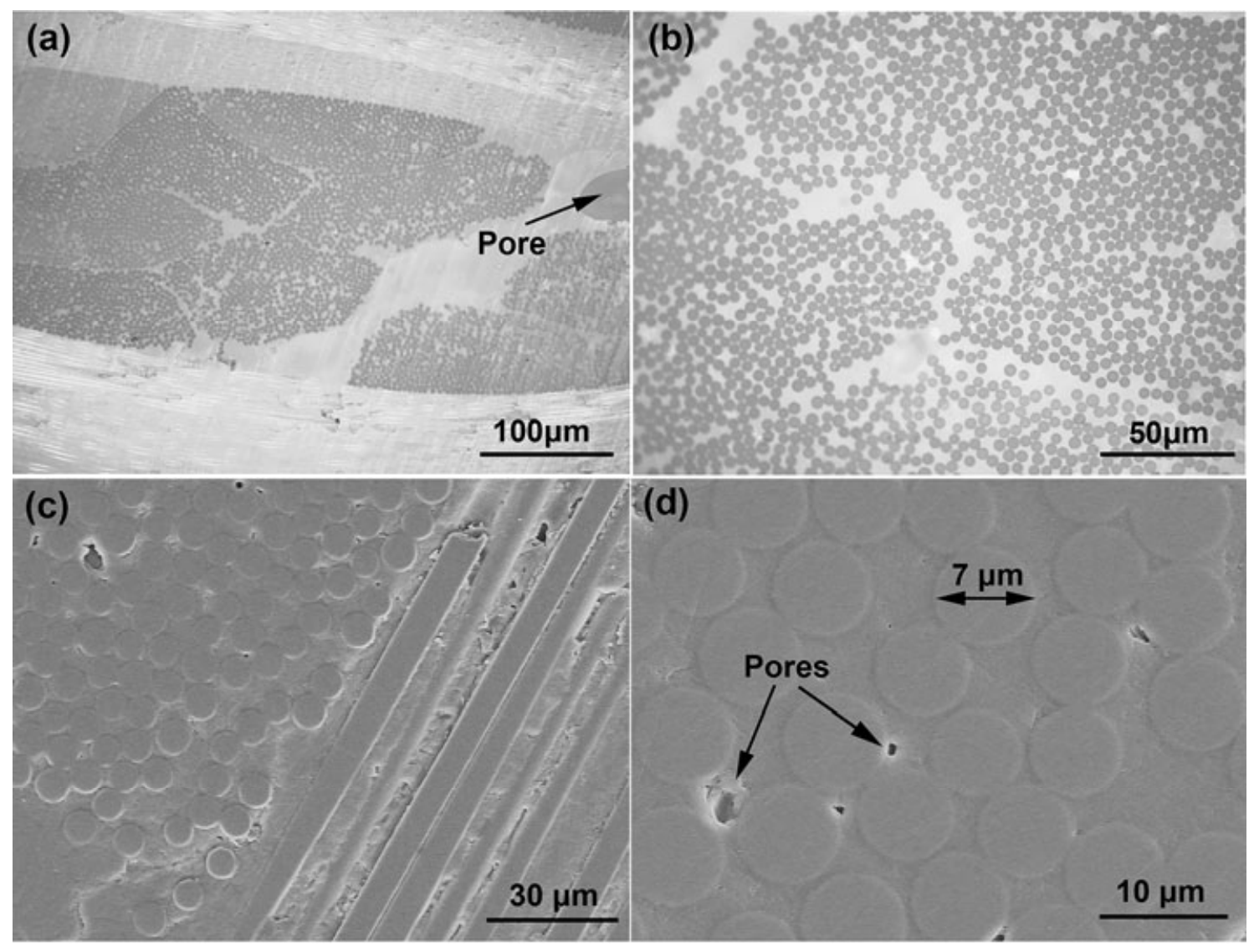

This article is protected by copyright. All rights reserved. 


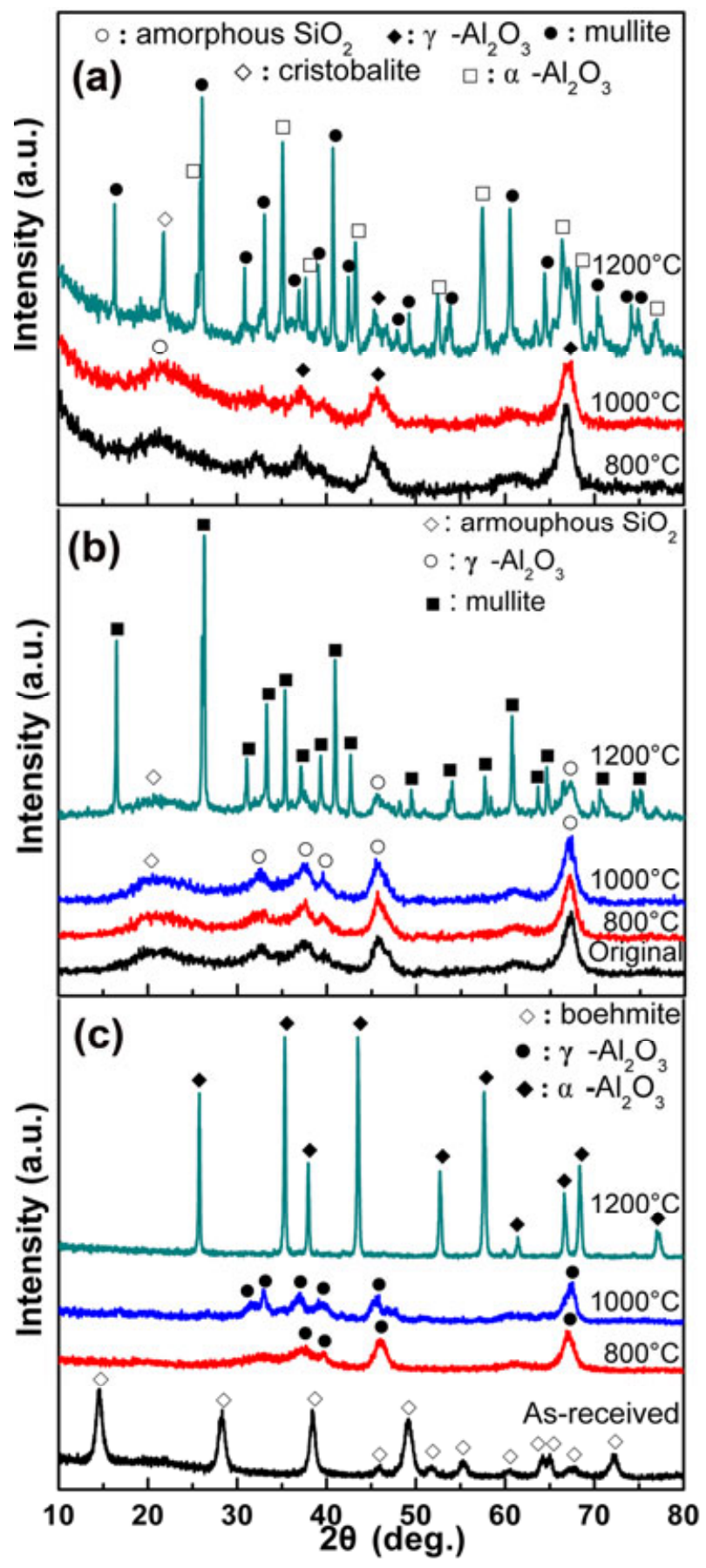

This article is protected by copyright. All rights reserved. 

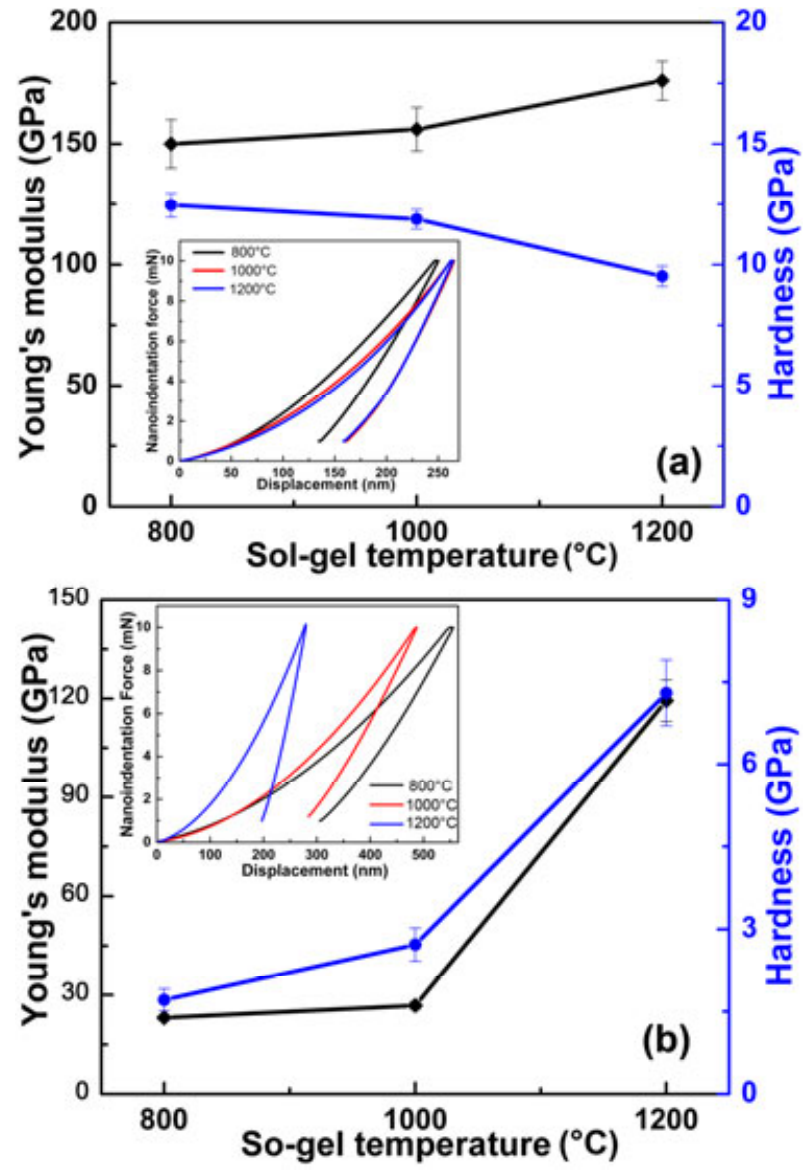

This article is protected by copyright. All rights reserved. 

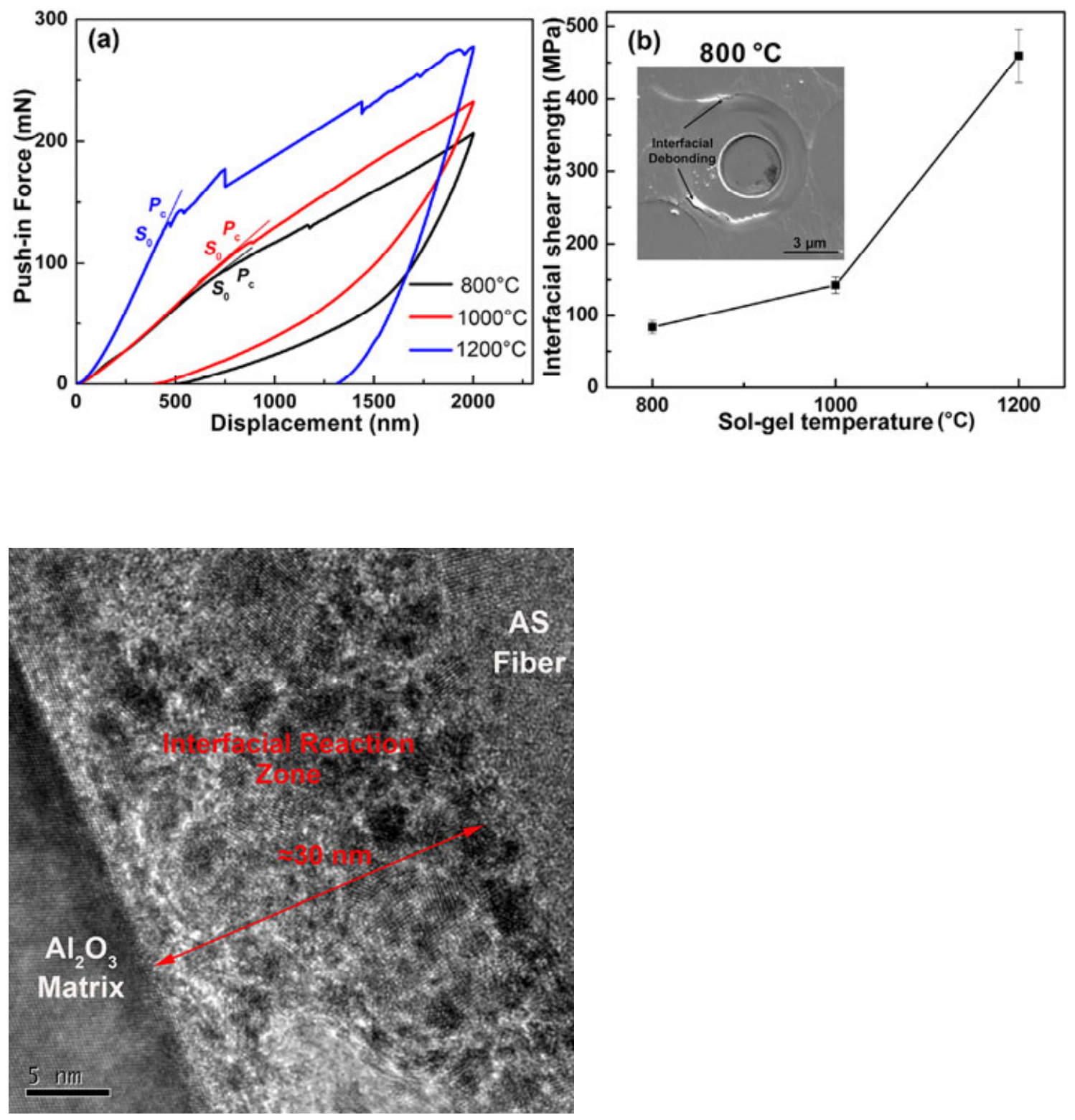

This article is protected by copyright. All rights reserved. 

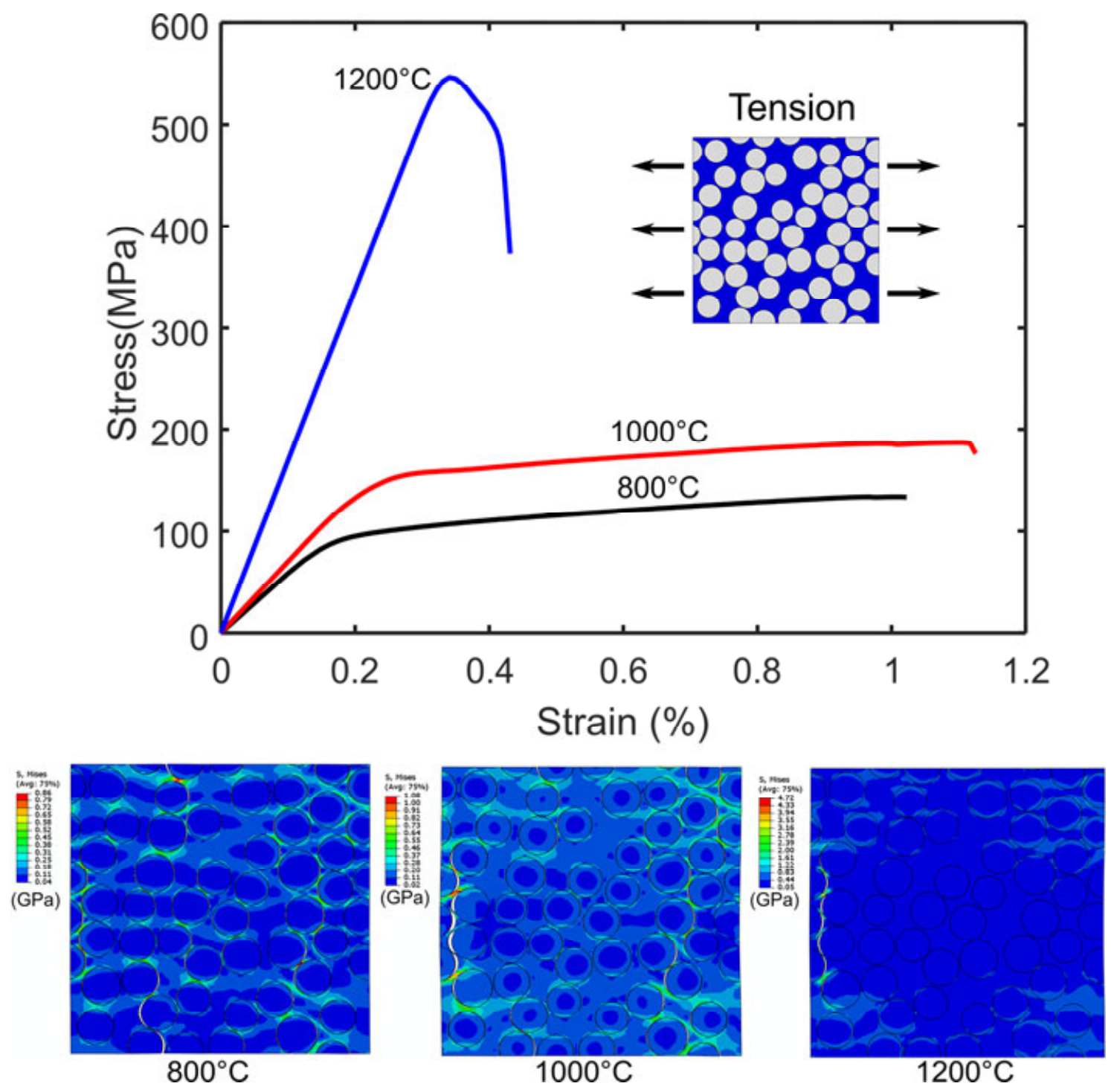

This article is protected by copyright. All rights reserved. 

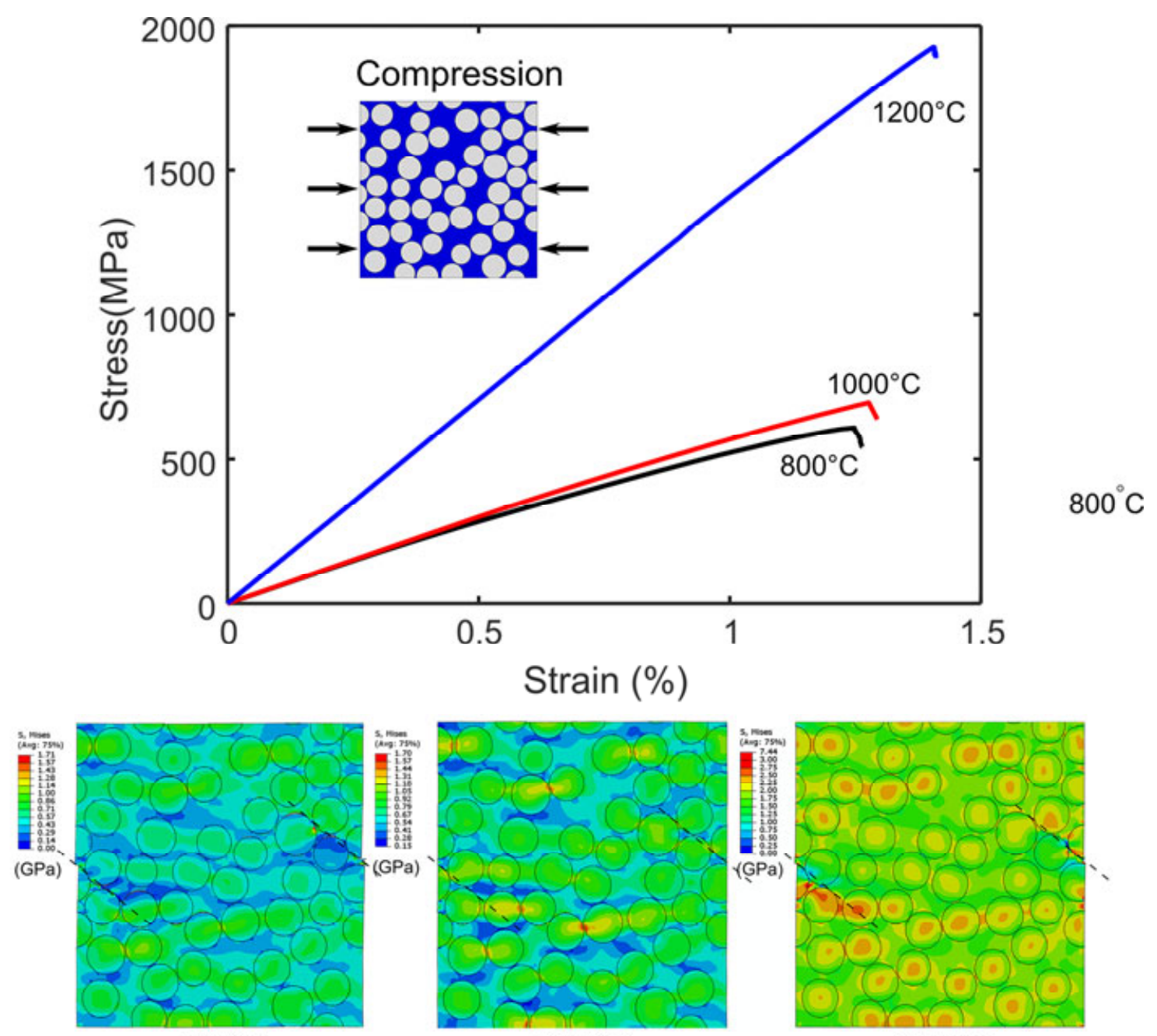

$800^{\circ} \mathrm{C}$

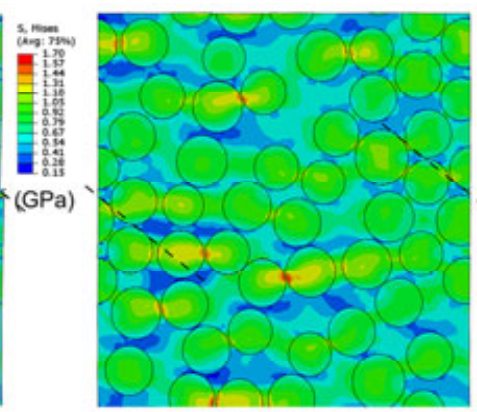

$1000^{\circ} \mathrm{C}$
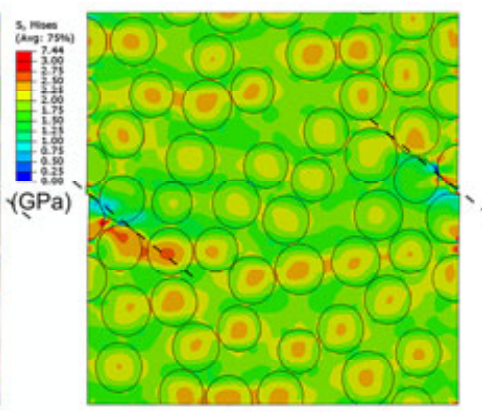

$1200^{\circ} \mathrm{C}$

This article is protected by copyright. All rights reserved. 


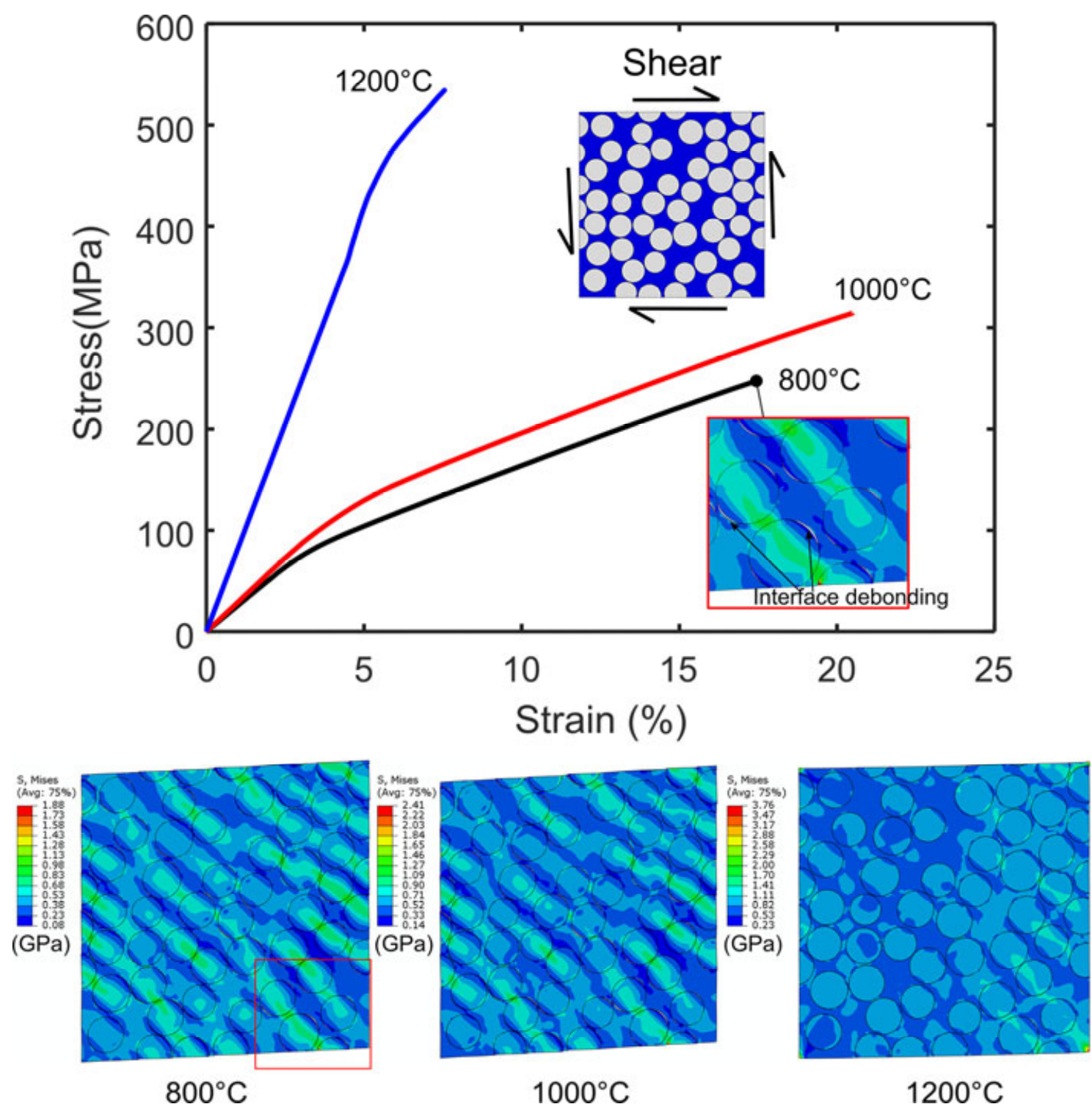

This article is protected by copyright. All rights reserved. 

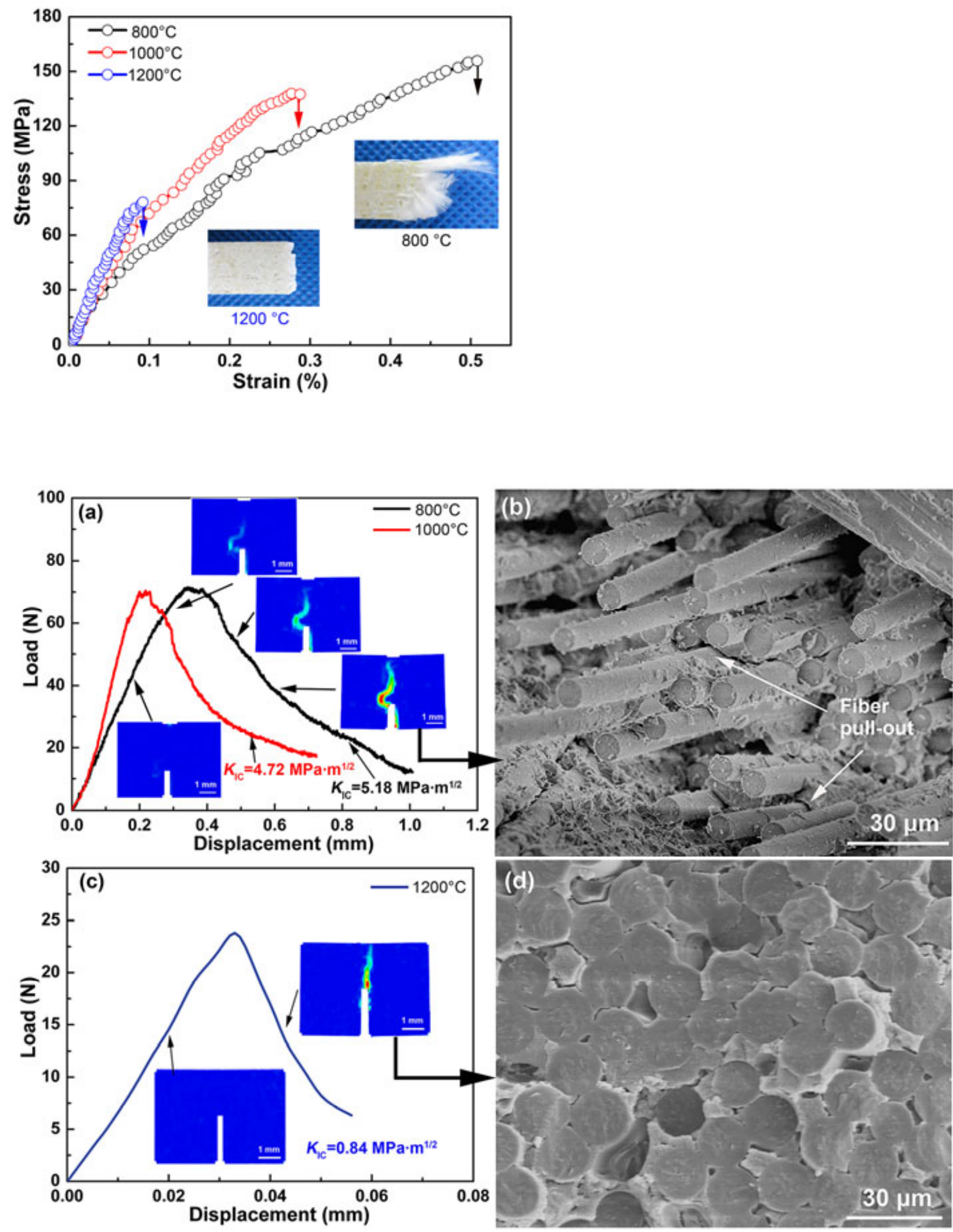

This article is protected by copyright. All rights reserved. 